\title{
Hyaluronan uptake by adult human skin fibroblasts in vitro
}

\author{
M.A. Croce, ${ }^{*}$ F. Boraldi, ${ }^{*}$ D. Quaglino, R. Tiozzo, I. Pasquali-Ronchetti \\ Department of Biomedical Sciences, University of Modena and Reggio Emilia, Italy
}

\section{(C)2003, European Journal of Histochemistry}

Low and high molecular weight hyaluronan (HA) was added to adult human fibroblasts grown in monolayer to assess its influence on CD44 expression, its internalisation and effect on cell growth. CD44 expression on the surface of in vitro fibroblasts was not modified by different concentrations of FCS, whereas it was sensitive to cell cycle, being higher in the growing than in the resting phase. Independently from molecular weight, upon addition of exogenous HA (from 0.1 up to $1 \mathrm{mg} / \mathrm{mL}$ ) to fibroblasts in the growing phase, a slight but constant decrease of the expression of CD44 on the surface of fibroblasts was observed; moreover, HA induced a rearrangement of CD44 into patches in close relationship with the terminal regions of stress fibers, which became thicker and more rigid after a few hours from the addition of $\mathrm{HA}$ to the medium. Fluorescent $\mathrm{HA}$, added to the culture medium, rapidly attached to the plasma membrane and in less than two minutes was observed within cells, partly in association with its receptor CD44. By the contemporary use of neutral red, which accumulates into functional lysosomes, the great majority of internalised HA was found within lysosomes. HA receptor RHAMM-IHABP was rather homogeneously localised within the cytoplasm of normal growing fibroblasts. Upon addition of HA, the RHAMM-IHABP distribution became discontinuous around the nucleus. Addition of $\mathrm{HA}$ to fibroblasts induced a significant inhibition of cell growth, which was dependent on HA concentration and irrespective of $\mathrm{HA}$ molecular weight, at least in the ranges tested. Results show that extra-cellular HA is rapidly taken up by human dermal fibroblasts together with its CD44 receptor, and transported mostly to the lysosomes. Both low and high molecular weight HA induced down-regulation of cell proliferation, which would seem to be mediated by HA catabolism.

Key words: CD44, confocal microscopy, flow cytometry, fibroblast, hyaluronan, hyaluronic acid, RHAMM-IHABP.

Correspondence: Prof. Ivonne Pasquali-Ronchetti, Dipartimento di Scienze Biomediche, Università di Modena e Reggio Emilia, via Campi 287, 41100, Modena, Italy. Phone: international +39.059.2055418. Fax: international +39.059.2055426. E-mail: ronchetti.ivonne@unimore.it

*These authors equally contributed to this work.

Paper accepted on October 5, 2002

European Journal of Histochemistry 2003; vol. 47 issue 1 [Jan-Mar]:63-74
$\mathrm{H}$ yaluronan (HA) is a polymer made of repeated disaccharidic units (glucuronic acid and acetyl-glucosamine) present in the extra-cellular matrix of almost all connective tissues. It is synthesised by hyaluronate synthases localised on the plasma membrane of eukariotic (Fraser et al. 1997) and of some procariotic cells (Fraser et al. 1997; Jones et al. 1994). Its production has been shown to be regulated by a number of growth factors and cytokines, such as PDGF, TGF$\beta, F G F-2$, phorbol esters, TNF- $\alpha$, IL-1 $\beta$ (Asplund et al. 1993; Ellis et al. 1999; Heldin et al. 1992; Sugiyama et al. 1998; Suzuki et al. 1995; Teder et al. 1995; Tufvesson and Westergren-Thorsson 2000). HA is mainly produced during embryogenesis (Toole, 1997; Wheatly et al. 1993), in the early stages of wound repair (Entwistle et al. 1996) and can be found in considerable amounts in metastatic tumors (Kogerman et al. 1997; Rudzki and Jothy 1997; Tuszynski et al. 1997; Zhang et al. 1995). HA is also present within the cytoplasm and in the nucleus, where it seems to play a role in nucleolar function (Evanko and Wright 1999).

The biological role of $\mathrm{HA}$ must be rather important as it is present in all normal adult connective tissues (Fraser et al. 1997; Laurent and Fraser 1992), where, apart from conferring peculiar physico-chemical and visco-elastic properties to the extra-cellular milieu (Fraser et al. 1997), it interacts with a number of different cell types through cell surface CD44 receptors (Entwistle et al. 1996; Fraser et al. 1997; Knudson and Knudson 1993; Savani et al. 1995; Toole 1997; Van de Stolpe and

\footnotetext{
Abbreviations

DMEM, Dulbecco Modified Eagle Medium; FGF, Fibroblast Growth Factor; HA, Hyaluronan or Hyaluronic Acid; CD44, hyaluronan receptor CD44; PDGF, Platelet Derived Growth Factor; PE, Phyco-Erythrin; RHAMM-IHABP, Receptor for Hyaluronan Mediated Motility-Intracellular Hyaluronan Binding Protein; TGF, Tumor Growth Factor; TNF, Tumor Necrosis Factor.
} 
Van der Saag 1996; Aguiar et al., 1999).

Production of $\mathrm{HA}$ and binding of $\mathrm{HA}$ to cell receptors have been shown to be regulated in a rather complex way, depending on the cell type and on physiological or pathological conditions (Levesque and Haynes 1997; Mohamadzadeh et al. 1998). Moreover, HA has been shown to be internalised by cells and to modulate cell functions (Croce et al., 2001). The role of HA on cell functions has been attributed mainly to its low molecular weight fragments derived by cleavage, enzymatic or not, of the high molecular weight polymer synthesised by cells. These fragments seem to have pleiotropic functions, such as induction or inhibition of cell proliferation (Gressner 1991; Rahmanian et al. 1997; Rooney et al. 1995; Sattar et al. 1994; Trochon et al. 1996), stimulation of nitric oxide synthase (Rockey et al. 1998), promotion of cell motility (Gressnetr 1991; Van de Stolpe and Van der Saag 1996) and cell adhesion (Clark et al. 1996; Legras et al. 1997; Savani et al. 1995; Toole 1997). However, data obtained by different authors are often rather contradictory and seem to depend mainly on the cell model used. A few studies have been done on normal human fibroblasts, that are good producers of HA especially during embryogenesis and wound repair. The aim of this study was to analyse the uptake of exogenous HA by normal human skin fibroblasts in culture and its effect on cell duplication.

\section{Materials and Methods}

Dermal biopsies from the armpit were obtained after informed and signed consent from 6, apparently healthy, subjects (age $39 \pm 6 \mathrm{yr}$ ) who underwent surgery for traumatic events. Sampling was approved by the Ethical Committee of the Faculty of Medicine of the University of Modena and Reggio Emilia (Italy). Fibroblast cultures were established according to Quaglino et al. (2000) and grown at $37^{\circ} \mathrm{C}$ in $5 \% \quad \mathrm{CO}_{2} / 95 \%$ air atmosphere. Cells were used between the third and the eighth passage. Routinely, fibroblasts were grown as mono-layer in $75 \mathrm{~cm}^{2}$ flasks (Nunc, Roskilde, Denmark). The G-0 phase was checked by flow cytometry. All chemicals were of analytical grade.

\section{Receptor and integrin expression}

Synchronised cells were grown in monolayer i) in the presence of $1 \%, 5 \%$ and $10 \%$ FCS (Gibco,
Australian origin); ii) in DMEM plus 10\% FCS and in the presence or absence of $0.1,0.5$ and $1 \mathrm{mg} / \mathrm{mL}$ HA of either $1.6 \times 10^{6}$ (Polytech, Trieste, Italy), 7.5 $\times 10^{5}$ (Fidia Spa, Abano Terme, Italy), and $1 \times 10^{3}$ (Polytech, Trieste, Italy) Da. HA was always added to the culture medium after 6 hours from cell seeding, to avoid any effect of HA on cell adhesion to the substrate. Moreover, cell detachment from the substrate upon addition of HA was checked by cell counting in the culture media.

Cells, grown for 24 hours in the presence or not of $\mathrm{HA}$, were detached from the substrate with 10 mM EDTA in PBS for 10 minutes at $37^{\circ} \mathrm{C}$, blocked by the same amount of PBS with calcium and magnesium and washed twice with PBS. In a number of experiments, cells were then treated with $50 \mathrm{U} / \mu \mathrm{L}$ testicular hyaluronidase type $\mathrm{V}$ (Sigma, St.Louis, MO) in DMEM without FCS, pH 6, for 60 minutes at $37^{\circ} \mathrm{C}$. Five $\times 10^{5}$ cells were suspended in $200 \mu \mathrm{L}$ PBS and incubated for 30 minutes at room temperature with $5 \mu \mathrm{L}$ of undiluted $\mathrm{PE}$-conjugated monoclonal antibody against CD44 (clone A3D8, Sigma, St. Louis, MO) or with antibodies towards RHAMM-IHABP (kindly provided by Dr. Volker Assmann, University of London) (Assmann et al. 1998) or with anti-integrin subunit $\beta 1$ antibodies (Chemicon, Temecula, CA). In these two latter cases, before incubation with antibodies, cells were or were not fixed with 3\% paraformaldehyde (Sigma, St Louis, MO) in PBS for 10 minutes at room temperature, washed in PBS, treated with 0.5\% Triton X100 (Merck, Frankfurt, Germany) for 10 minutes at room temperature, and washed again in PBS. After incubation with antibodies cells were washed in PBS, centrifuged and incubated for 30 minutes at room temperature with TRICTlabelled anti-rabbit IgG (Dako, Denmark) (for RHAMM-IHABP) or with FITC-labelled antimouse IgG (Dako, Denmark) (for anti- $\beta 1$ integrin subunit). Controls were established by using isotypic immunoglobulin or the secondary antibody alone. Cells were carefully washed in PBS, suspended in $250 \mu \mathrm{L}$ of $\mathrm{PBS}$ and analysed on a EPICS XL (Coulter, Miami, Florida). Debris and dead cells were excluded by forward and side scatter gating. Ten thousand events were collected and evaluated for each cell type using the WIN M DI 2.8 program. Experiments were performed in triplicate and repeated on cell strains from at least 3 different individuals.

For confocal microscopy (Leica TCS 4D, Germa- 
ny), cells were grown for 24 hours on glass multichamber slides (Nunc, Roskilde, Denmark) in the presence or in the absence of $1 \mathrm{mg} / \mathrm{ml}$ high and low molecular weight $H A$, washed twice in PBS and a) incubated or not with $\mathrm{PE}$-conjugated monoclonal antibody towards CD44 (Sigma, St Louis, M0) (1: 100 diluted) for 30 minutes at room temperature, washed with PBS, fixed with 3\% paraformaldehyde in PBS for 10 minutes at room temperature and observed by confocal microscopy; b) fixed with 3\% paraformaldehyde in PBS for 10 minutes at room temperature, washed in PBS, treated or not with $0.5 \%$ Triton $\mathrm{X} 100$ for 10 minutes at room temperature, washed in PBS, incubated with antibodies towards RHAMM-IHABP (1:100 diluted) for 30 minutes at room temperature, washed and then incubated with TRITC-conjugated secondary antibody for 30 minutes at room temperature, carefully washed in PBS and observed by confocal microscopy. Experiments were performed on cell strains from different subjects.

\section{Binding and internalisation}

Cells in the growing or in the resting phase were detached from tissue culture flasks as described above, washed twice with PBS, incubated with 0.1 , 0.5 and $1 \mathrm{mg} / \mathrm{ml}$ fluoresceinated $\mathrm{HA}$ of $8.5 \times 10^{4}$ Da in PBS for $1,10,20,30,60$ and 120 minutes at $37^{\circ} \mathrm{C}$ or at $4^{\circ} \mathrm{C}$, washed twice in PBS and observed by flow cytometry, as described above. As positive controls, cells were incubated with non-fluoresceinated HA $\left(8.5 \times 10^{4} \mathrm{Da}\right.$; Polytech, Trieste) at the same concentrations. As negative controls, cells were treated in parallel without any contact with HA. Experiments were repeated in duplicate on cell strains from different subjects.

Cells, grown on glass multi-chamber slides for 24 hours, were incubated in the presence or in the absence of $0.1,0.5$ and $1 \mathrm{mg} / \mathrm{mL}$ fluoresceinated $\mathrm{HA}$ of $8.5 \times 10^{4} \mathrm{Da}$ in PBS for $1,5,10$, and $20 \mathrm{~min}-$ utes at room temperature, carefully washed in PBS and observed by confocal microscopy. Localization of CD44, in relation to HA binding and internalisation, was analysed by confocal microscopy. Briefly, cells grown for 24 hours on glass multi-chamber slides were a) incubated with PE-conjugated antiCD44 antibodies ( $1: 100$ dilution) for 30 minutes at room temperature, washed in PBS, and then incubated with 0.5 and $1 \mathrm{mg} / \mathrm{mL} 8.5 \times 10^{4}$ Da fluoresceinated $\mathrm{HA}$ for $1,5,10,20$ minutes at room temperature; b) incubated with 0.5 and $1 \mathrm{mg} / \mathrm{mL} 8.5$ $\times 10^{4}$ Da fluoresceinated $\mathrm{HA}$ for $1,5,10,20$ minutes at room temperature and then incubated with PE-conjugated anti-CD44 antibodies (1:100 dilution) for 30 minutes at room temperature. In both cases, after repeated washes with PBS, cells were briefly fixed with 3\% paraformaldehyde, carefully washed in PBS and observed by confocal microscopy. Red and green signals revealed the presence of CD44 and HA, respectively.

Due to the characteristics of anti-RHAMMIHABP antibodies, RHAMM-IHABP expression and localisation, in relation to $\mathrm{HA}$ binding and internalisation, was revealed according to the following procedure: cells, grown to sub-confluence as above, were incubated or not with 0.5 and $1 \mathrm{mg} / \mathrm{mL}$ $8.5 \times 10^{4} \mathrm{Da} H A$ for $1,5,10$ and 20 minutes at room temperature, washed in $\mathrm{PBS}$, fixed with $3 \%$ paraformaldehyde in PBS for 10 minutes at room temperature, washed in PBS, treated with $0.5 \%$ Triton $\mathrm{X} 100$ for 10 minutes at room temperature, washed in PBS, incubated with the polyclonal RHAMM-IHABP antibodies for 30 minutes at room temperature, washed twice in PBS, incubated with TRICT-conjugated secondary antibodies for 30 minutes at room temperature, carefully washed in PBS and observed by confocal microscopy. Experiments were performed on cell strains from different individuals.

\section{Cytoskeleton}

Cells were cultured for 24 hours on glass multichamber slides (Nunc, Roskilde, Denmark) in the presence or not of $1.6 \times 10^{6} \mathrm{Da} \mathrm{HA}(1 \mathrm{mg} / \mathrm{mL}$ ) (Polytech, Trieste). After $24 \mathrm{hr}$ cells were fixed with $3 \%$ paraformaldehyde in PBS for 20 min at room temperature, carefully washed in PBS, treated with $0.5 \%$ Triton $X-100$ in PBS for 10 min, washed with PBS, incubated with $4 \mu \mathrm{g} / \mathrm{mL}$ FITC-conjugated phalloidin for $1 \mathrm{hr}$ at room temperature, or incubated with monoclonals towards human vimentin (clone VIM 13.2; Sigma, St.Louis, MO, USA) (1:50 diluted) or towards human vinculin (clone hVIN-1, Sigma, St. Louis, M0, USA) (1:25 diluted) for $60 \mathrm{~min}$ at $37^{\circ} \mathrm{C}$. In these two latter cases, after washings in PBS, cells were incubated with anti-mouse anti-antibodies conjugated with either fluorescein or R-phycoerythrin (Sigma, St.Louis, $\mathrm{MO}$, USA), respectively, for $60 \mathrm{~min}$ at $37^{\circ} \mathrm{C}$. In all cases, cells were carefully washed in PBS and observed by confocal microscopy. In separate experiments, cells grown in the presence or in the 
absence of high molecular weight $\mathrm{HA}$, as above, were incubated with R-phycoerythrin-conjugated polyclonal antibodies against CD44 (1:200 diluted) for 30 min at $37^{\circ} \mathrm{C}$, washed with PBS, fixed in $3 \%$ formaldehyde in PBS for 5 min at room temperature, washed again, treated with $0.1 \%$ Triton $X-100$ in PBS for 3 min at room temperature and then incubated in the presence of $4 \mu \mathrm{g} / \mathrm{mL}$ FITCconjugated phalloidin (Molecular Probes, Eugene, USA) for 30 min at room temperature. After washing in PBS, cells were observed by fluorescence (Zeiss, Axiophot) or confocal microscopy (Leica, Laser TCS 4D, Wetzlar, Germany).

\section{Lysosome staining}

Lysosomes were stained by the neutral red method that is based on the uptake of the stain by the lysosomes of living cells. Fibroblasts were cultured for 12 $\mathrm{hr}$ in multi-chamber culture slides in DMEM and $10 \% \mathrm{FBS}$ and then in DMEM without FBS for further 12 hr. A 0.4\% Neutral Red (Sigma, St.Louis, MO, USA) solution was prepared in DMEM without FBS and centrifuged at $1500 \mathrm{~g}$ for 10 minutes, in order to remove insoluble crystals. Fresh solutions were prepared for each assay. Cells were rinsed with PBS and incubated with DMEM plus neutral red for $3 \mathrm{hr}$ at $37^{\circ} \mathrm{C}$. Cells were then incubated in DMEM and neutral red plus fluoresceinated HA $\left(8.5 \times 10^{4}\right.$ $\mathrm{Da}$, Polytech, Trieste) at the final concentration of 1 $\mathrm{mg} / \mathrm{mL}$, for $5,10,20$ and 30 minutes at $37^{\circ} \mathrm{C}$, the neutral red was removed and cells rinsed with $1 \mathrm{~mL}$ of wash/fix solution $(1,3 \mathrm{~mL}$ of $37 \%$ formaldehyde and $10 \mathrm{~mL}$ of a $10 \%$ solution of anhydrous $\mathrm{CaCl}_{2}$ in $89 \mathrm{~mL}$ of distilled water) for 2-3 minutes. Cells were observed with a Zeiss Axiophot light microscope equipped with two cameras allowing recording of the same cell under transmitted light (neutral red) and under UV light for FITC-HA. Final images were obtained by using an Adobe Photoshop ${ }^{\circledR}$ software program combining the two digital images of the same cells. Artificial colours have been attributed to the following structures: black to lysosomes, white to HA, grey to HA co-localized with lysosomes.

\section{Cell duplication}

$1.2 \times 10^{5}$ cells were cultured into $35 \mathrm{~mm}$ Petri dishes (Falcon, Franklin Lakes, NJ, USA) in $2 \mathrm{~mL}$ DMEM containing $10 \%$ FCS. Cells were grown in the presence and in the absence of $0.1,0.5$, and 1 $\mathrm{mg} / \mathrm{mL}$ HA of $1.6 \times 10^{6}, 7.5 \times 10^{5}, 1 \times 10^{3} \mathrm{Da}$, which was added after $6 \mathrm{hr}$ from seeding. HA was added once on the first day or freshly every day by changing the culture medium. After 1, 2, 3 and 4 days of culture, the medium was collected and cells were detached by $0,25 \%$ trypsin for 10 min, centrifuged, suspended in a small amount of medium and counted by the Neubauer chamber.

To avoid errors due to the influence of HA on cell adhesion to the substrate, floating cells were collected from the medium by centrifugation and counted as above every day. Experiments were always performed in triplicate and were repeated on the different cell strains.

\section{Cell cycle}

After assessment of the G-0 state by flow cytometry on cells grown in parallel, cells were detached by $0.25 \%$ trypsin for $10 \mathrm{~min}$, and seeded into $25 \mathrm{~cm}^{2}$ flasks with DMEM, 10\% FCS in the presence or in the absence of $0.5 \mathrm{mg} / \mathrm{mL} 1.6 \times 10^{6}$ and $7.5 \times 10^{5} \mathrm{Da}$ HA. After 24, 48 and $72 \mathrm{hr}$ culture, the cell cycle was assayed by incubation with $10 \mathrm{mM}$ bromodeossiuridine (BrdU) (Sigma, St. Louis, M0, USA) for 30 minutes at $37^{\circ} \mathrm{C}$. Cells were then trypsinized, suspended in DMEM, treated with $0.5 \%$ Tween 20 (Merck, Frankfurt, Germany) in PBS, centrifuged at $2000 \mathrm{rpm}$ for 5 minutes, suspended in 0,5 mL 0.5\% Tween 20 in PBS and in $0.5 \mathrm{~mL} 4 \mathrm{~N} \mathrm{HCl}$ and incubated for 30 minutes at room temperature. After centrifugation, cells were suspended in $1 \mathrm{~mL} 0.1 \mathrm{M}$ Borax (Riedel-de Haen), centrifuged, incubated for 1 hour at $4^{\circ} \mathrm{C}$ in $200 \mu \mathrm{L} 0.5 \%$ Tween 20 in PBS and in $5 \mu \mathrm{L}$ anti-BrdU monoclonal antibody (Becton Dickinson, San Josè, CA, USA), centrifuged, incubated for 30 minutes at $4^{\circ} \mathrm{C}$ in $200 \mu \mathrm{L} 0.5 \%$ Tween 20 in PBS and $5 \mu \mathrm{L}$ of fluoresceinated antiimmunoglobulin (GAM-FITC) (Becton Dickinson, USA), centrifuged, incubated for 20 minutes at $4^{\circ} \mathrm{C}$ in $200 \mu \mathrm{L} 0.5 \%$ Tween 20 in PBS and in $200 \mu \mathrm{L}$ propidium iodide (Sigma, St. Louis, MO, USA) and finally analysed on a EPICS XL (Coulter, Miami, Florida). Experiments were done in triplicate and repeated on different cell strains.

\section{Results}

\section{CD44 expression}

CD44 was highly expressed on the surface of human dermal fibroblasts grown in mono-layer (Figure 1). Its expression was not modified by treatment with hyaluronidase (not shown) and was 
insensitive to the presence or not of FCS in the culture medium (Figure 1a); as a positive control, in the same experimental conditions, the expression of the $\beta$ - 1 integrin subunit was observed to be influenced by serum concentration (Figure la). Allowing for differences among cell lines, CD44 expression depended on the cell cycle being always higher in proliferating cells compared to the same cells at confluence (Figure $1 b ; p<0.05$ ).

By confocal microscopy, CD44 was shown to form a rather uniform coat on the surface of human dermal fibroblasts (Figure 2a). Upon addition of HA to the culture medium the expression of CD44 on the plasma membrane appeared weaker and more discontinuous (Figure $2 \mathrm{~b}$ ). Flow cytometry revealed that more than $90 \%$ of cells were positive for CD44, that CD44 was rather variable among subjects, and decreased upon addition of HA to the culture medium (Figure 2c). The decrease was appreciated at a HA concentration as low as $0.1 \mathrm{mg} / \mathrm{mL}$ and was independent from the $\mathrm{HA}$ molecular weight (not shown). By using $1 \mathrm{mg} / \mathrm{mL} H A$, the decrease was statistically significant within the same cell strain (Figure 2c).

\section{HA binding and internalisation}

Cells grown in monolayer were assayed for their capacity to bind and internalise fluorescent $\mathrm{HA}$ added to the culture medium for times from 1 up to
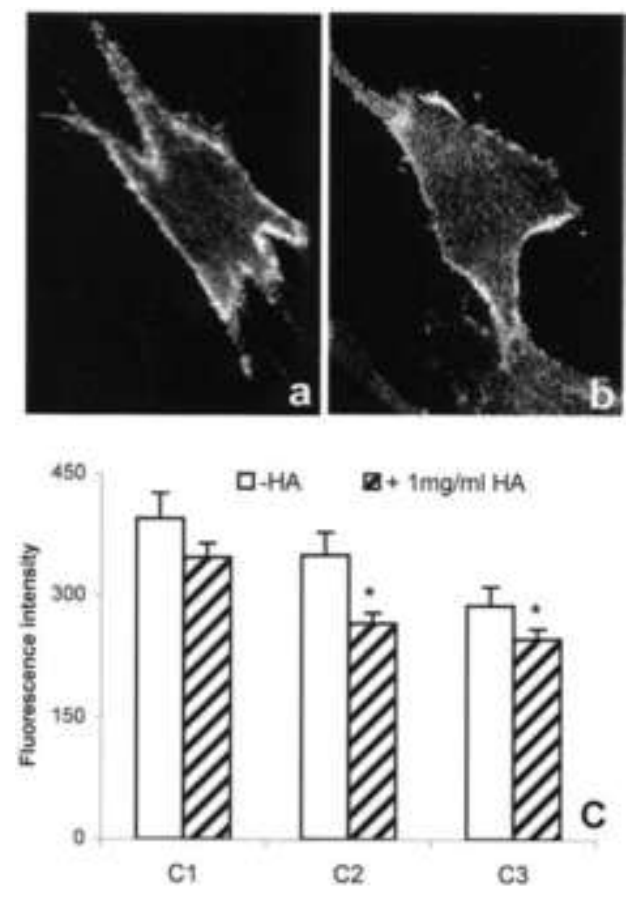
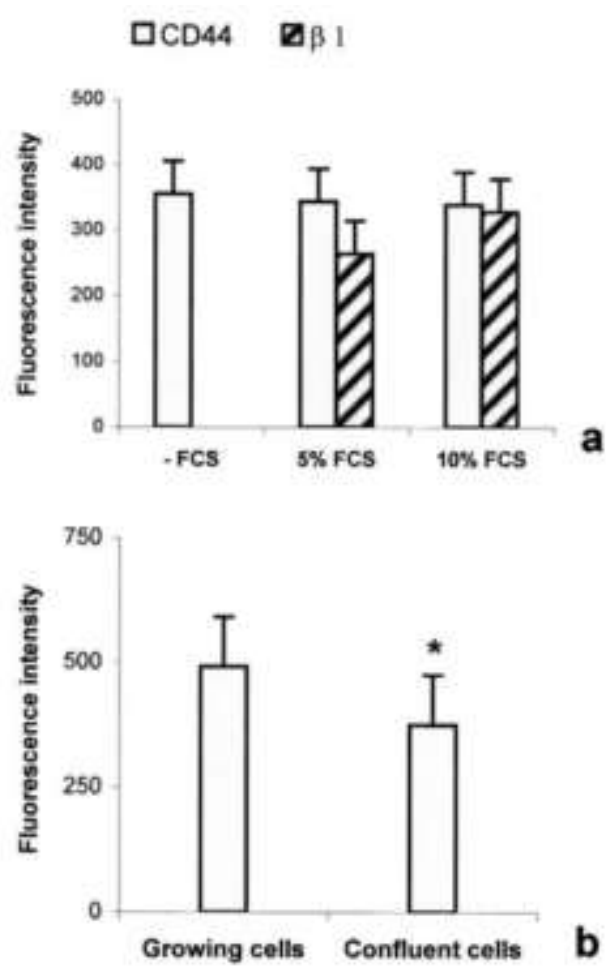

Figure 1. CD44 and $\beta-1$ integrin subunit expression by human dermal fibroblasts in vitro. As expected, the expression of the $\beta-1$ subunit was influenced by serum concentration ( $5 \%$ vs $10 \%$ FCS, p<0.05) (a). In contrast, CD44 expression was independent from serum concentration since changes were negligible even in its absence (a). Interestingly, CD44 expression was significantly lower in cells at confluence compared to growing cells $\left({ }^{*} p<0.05\right)(b)$. Data were obtained by flow cytometry from different individuals.

\begin{abstract}
Figure 2. CD44 expression of human dermal fibroblasts in vitro, revealed by confocal microscopy $(a, b)$ and by flow cytometry (c). After 1 minute from the addition of high molecular weight $\mathrm{HA}(1 \mathrm{mg} / \mathrm{mL})$ to the culture medium (b) CD44 labelling was less homogeneously distributed and less evident on the cell surface compared to cells grown in the absence of HA (a). By flow cytometry, the expression of CD44 was always lower in the presence of HA. Figure 2c illustrates cytofluorimetric data obtained on cell strains from 3 different individuals upon addition of $1 \mathrm{mg} / \mathrm{mL}$ HA $\left(1.6 \times 10^{6} \mathrm{Da}\right)$ $\left({ }^{*} p<0.05\right)$.
\end{abstract}



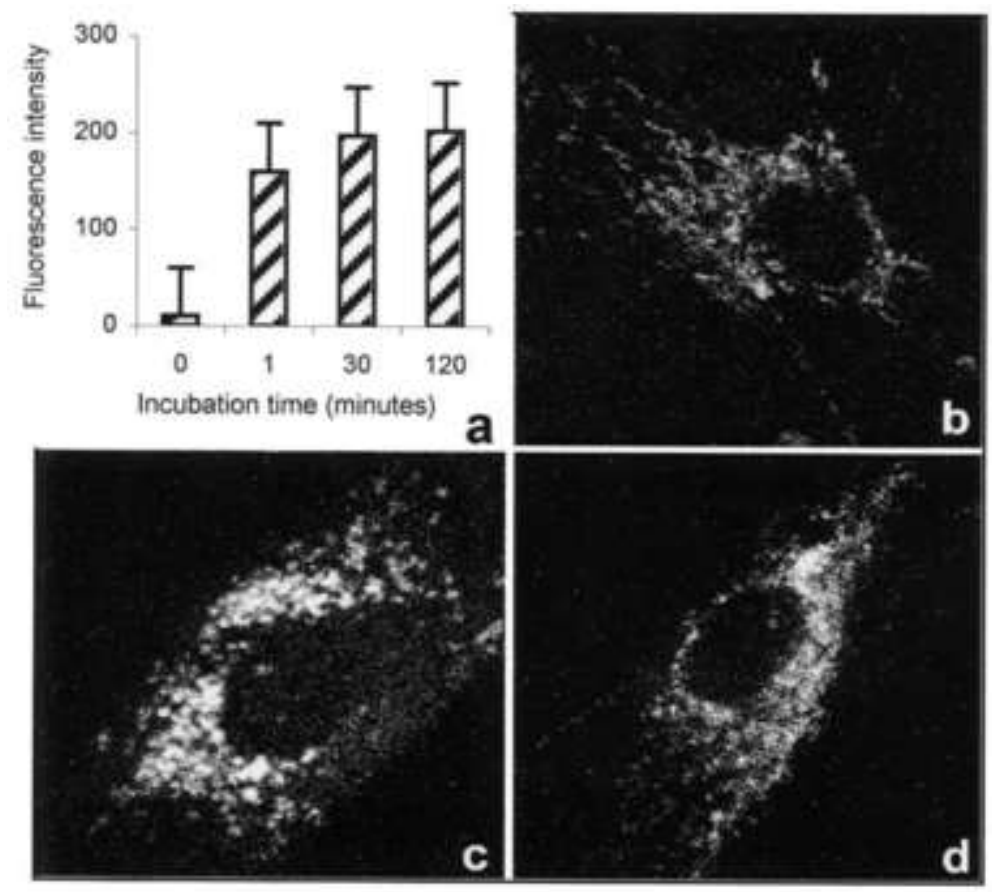

Figure 3. Uptake of fluoresceinated HA by invitro human dermal fibroblasts. Already after 1 minute incubation fluorescent HA was already within cells, as revealed by flow cytometry (a) and confocal microscopy (b). Moreover, confocal microscopy showed that after 10 (c) and 20 (d) minutes incubation HA accumulated in discrete globules in the peri-nuclear area. Experiments were repeated on cells from different individuals.

60 minutes and at HA concentrations of $0.1,0.5$, and $1 \mathrm{mg} / \mathrm{mL}$. After incubation, fluorescent cells were observed by confocal microscopy and the phenomenon quantified by flow cytometry. Cells appeared fluorescent already after 1 minute incubation, the maximum intensity being reached within 30 minutes (Figure 3a). Binding was independent from the incubation temperature $\left(37^{\circ} \mathrm{C}\right.$ or $4^{\circ} \mathrm{C}$, not shown), indicating that the process was at least partially dependent on physico-chemical forces. By confocal microscopy, within 1 minute at $37^{\circ} \mathrm{C}$ fluorescent HA was observed within the cytoplasm (Figure 3b); after 10 minutes incubation with fluorescent $\mathrm{HA}$, the cytoplasm appeared intensively stained, especially in the peri-nuclear area (Figure 3c). After 20 minutes incubation, fluorescent HA was mostly concentrated in regions near the nucleus (Figure $3 d$ ). Figure 4 shows that uptake of HA was associated with internalisation of CD44 and that the antibodies towards CD44 used in the present study did not prevent HA binding and internalisation. As mentioned, already after 1 minute incubation at $37^{\circ} \mathrm{C}$, some fluorescent $\mathrm{HA}$ (green) could be observed inside the fibroblasts, whereas CD44 (red) was still on the cell surface (Figure 4a), suggesting that HA entrance into the cell was very rapid and at least partially independent from CD44. However, for longer times, HA uptake was associated with internalisation of CD44, as after
10 minutes incubation with fluorescent HA both receptor and ligand were found inside the cell and colocalized within the cytoplasm (yellow) (Figure 4b). Concomitant computerised visualization within the same cells of fluorescent HA and of lysosomes, these latter identified by the neutral red method (Figure 5 ), showed that, after 20 minutes from the addition of HA to the culture medium, about $60 \%$ of internalised HA was within lysosomes (grey), while the remaining $40 \%$ was present in discrete regions of the cytoplasm (white). Moreover, about $50 \%$ of lyso-
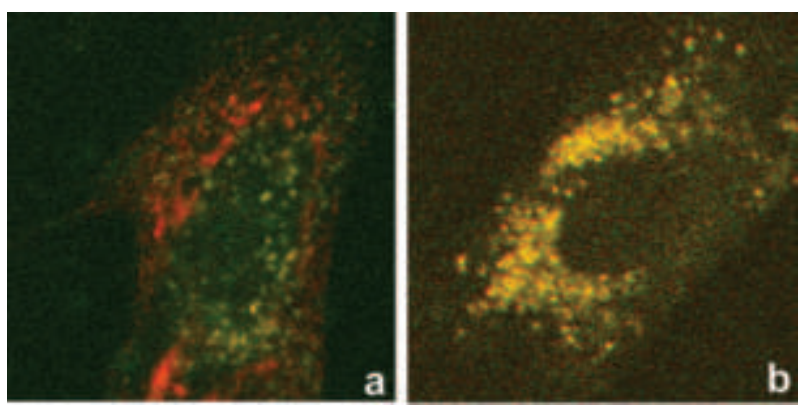

Figure 4. Hyaluronan (green) and CD44 (red) localization after incubation of cells with fluoresceinated HA. After 1 minute incubation, hyaluronan was found inside the cells, whereas the great majority of CD44 was still on the cell surface (a). After 10 minutes incubation, both CD44 receptor and fluorescent HA colocalised (yellow) within the cytoplasm as revealed by middle sections of cells by confocal microscopy. Experiments were repeated on cells from different individuals. 


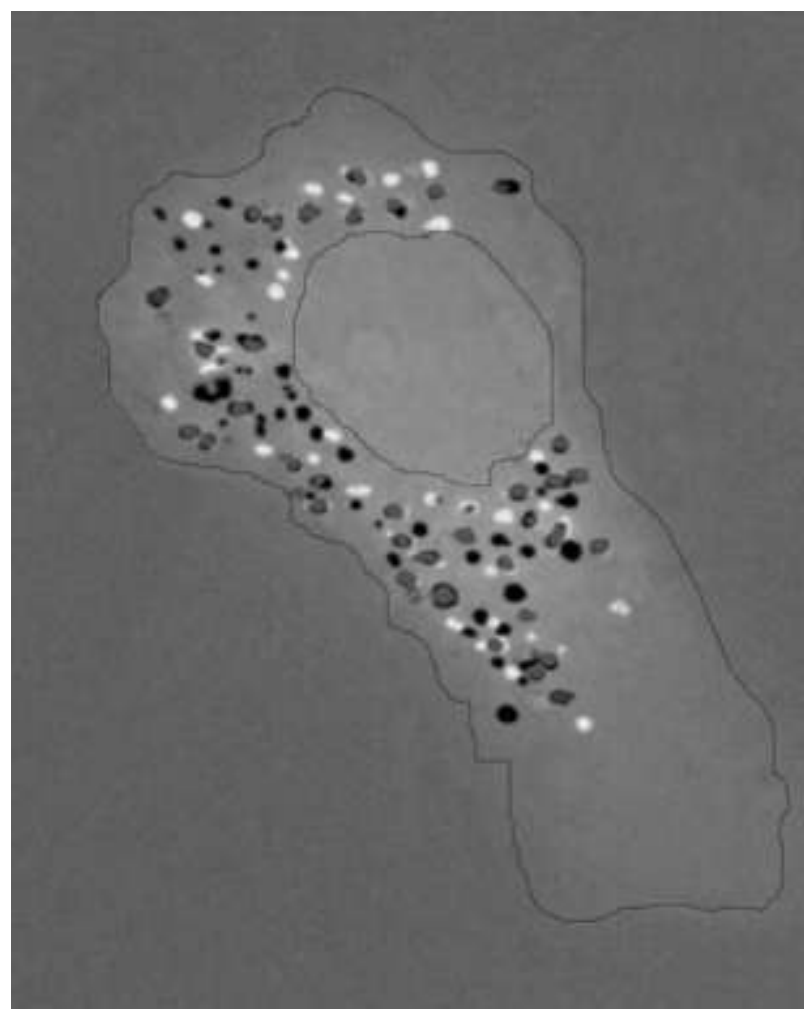

Figure 5. Computerised visualization of fluorescent HA (white) and of lysosomes (black) within a dermal fibroblast invitro after 10 minutes incubation in the presence of $0.5 \mathrm{mg} / \mathrm{mL}$ fluoresceinated HA. Lysosomes were visualised by the neutral red method (see Materials and Methods). Grey globules represent computerised co-localization of HA and lysosomes.

somes (black) did not seem to contain HA.

The HA receptor RHAMM-IHABP did not appear to be involved in HA uptake, however its cellular distribution was affected by HA internalisation. In normal growing conditions, RHAMMIHABP was negative on the surface of fibroblasts, whereas it was highly expressed within the cytoplasm (Figure 6a). When cells were maintained in the presence of $1 \mathrm{mg} / \mathrm{mL} \mathrm{HA}$ for times longer than 20 minutes, corresponding to the highest HA uptake observed in our experimental conditions, RHAM M-IHABP was still highly represented in the cytoplasm; however its distribution was not as uniform as in the absence of HA and was mainly concentrated into globules in the peri-nuclear area (Figure 6b).

Cell attachment and spreading were apparently unaffected by $\mathrm{HA}$ up to a concentration of 1 $\mathrm{mg} / \mathrm{mL}$. HA added to the culture medium of cells already attached to the substrate did not disturb cell
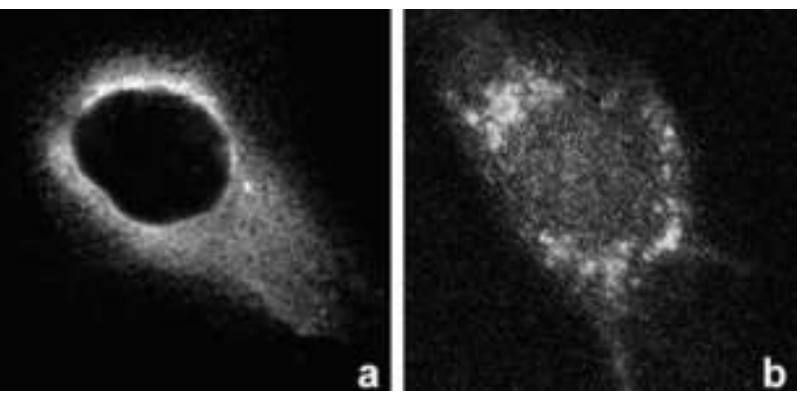

Figure 6. RHAMM-IHABP localisation revealed by confocal microscopy in the absence (a) and after $\mathbf{2 0}$ minutes incubation with fluoresceinated HA (b). In the absence of HA, RHAMMIHABP was mainly localised in the perinuclear area and its distribution was rather dispersed (a); after HA uptake, the receptor distribution appeared deeply modified (b). Experiments were repeated on cell strains from different subjects.

attachment, as evaluated by cell counting in the medium, nor cell spreading evaluated by light microscopy. The overall organization of cells as well as the vimentin-positive cytoskeleton and the vinculin-positive focal adhesions were almost identical in the absence and in the presence of HA (Boraldi et al. in press). By contrast, HA in the culture medium greatly enhanced the aggregation of actin into thick and rigid cables (Figures $7 a$ and $b$ ).

\section{Cell growth}

Cell attachment to the substrate was not affected by the presence of HA in the culture medium, as no cells were found in the medium collected at different times from $6 \mathrm{hr}$ up to 4 days of culture. By contrast, already after one day of culture, the number of cells attached to the substrate was significantly lower in the presence than in the absence of HA in
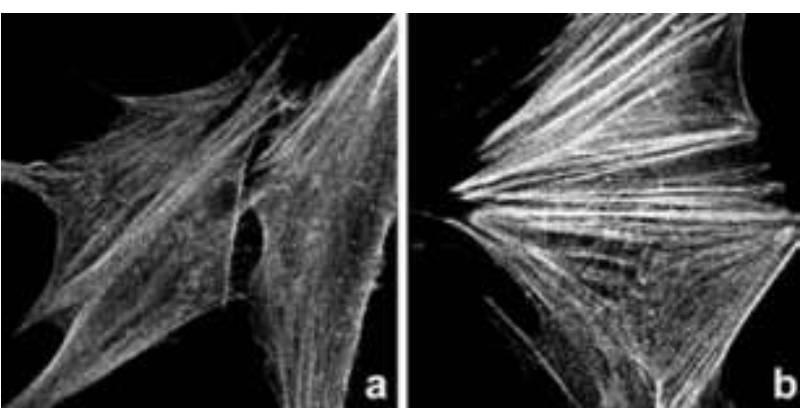

Figure 7. Dermal fibroblasts grown for $24 \mathrm{hr}$ in the absence (a) and in the presence (b) of $1 \mathrm{mg} / \mathrm{mL} \mathrm{HA}\left(1.6 \times 10^{6} \mathrm{Da}\right)$ in the culture medium. Cells grown in the presence of HA exhibited an actin cytoskeleton, revealed by fluorescent falloidin, more evident and formed by thicker bundles compared to controls. 
the culture medium and remained significantly lower up to the fourth day of culture (Figure 8). Inhibition of cell growth was dependent on the concentration of HA. By using $7.5 \times 10^{5} \mathrm{Da} \mathrm{HA}$, inhibition could be already appreciated at $0.1 \mathrm{mg} / \mathrm{mL} \mathrm{HA}$ (not shown) and was statistically significant at concentrations higher than $0.5 \mathrm{mg} / \mathrm{mL}$ (Figure 8 ). The effect was not influenced by HA added once at the beginning of the experiment or every day by changing the culture medium containing fresh HA (data not shown). Very similar effects were observed in the presence of higher $\left(1.6 \times 10^{6}\right)$ and lower $\left(1 \times 10^{3}\right)$ molecular weight HA (data not shown). As already mentioned, the lower number of cells in the presence of HA was not due to cell detachment from the substrate upon addition of soluble $\mathrm{HA}$, as revealed by cell counting in the medium from 6 up to 96 hours from the addition of HA (data not shown) nor to cell death or apoptosis as evaluated by flow cytometry (not shown). Analysis of the cell cycle showed that a $10 \%$ to $25 \%$ lower number of cells entered the cell cycle in the presence of $\mathrm{HA}$.

\section{Discussion}

HA is an ubiquitous component of the extra-cellular matrix and several data in the literature indicate that, besides its role in the organization of the extra-cellular matrix, it affects cell behaviour and metabolism, especially when present at high concentration such as in the course of development, in the early phases of inflammation and wound repair (Chen et al. 1989; Ohkawa et al. 1999) as well as in tumors (Knudson et al. 1989; Ropponen et al. 1998). In consideration of the abundance of HA in all connective tissues and its increase in the early phases of wound repair, it seemed of interest to investigate its interactions with normal fibroblasts and its eventual role in some basic processes involved in tissue repair, such as cell duplication and collagen synthesis.

In a previous study we have shown that relatively high concentrations of HA in the extra-cellular space inhibit collagen synthesis by normal human dermal fibroblasts (Croce et al, 2001). The present study concerns the ability of the normal human dermal fibroblast to bind and internalise $\mathrm{HA}$ and the effect of HA uptake on cell duplication. The data indicate that, in normal fibroblasts, HA receptor CD44 is highly involved in the uptake and transport of $\mathrm{HA}$ to lysosomes where it is probably degraded. In particular, data show that CD44 is constitutive-

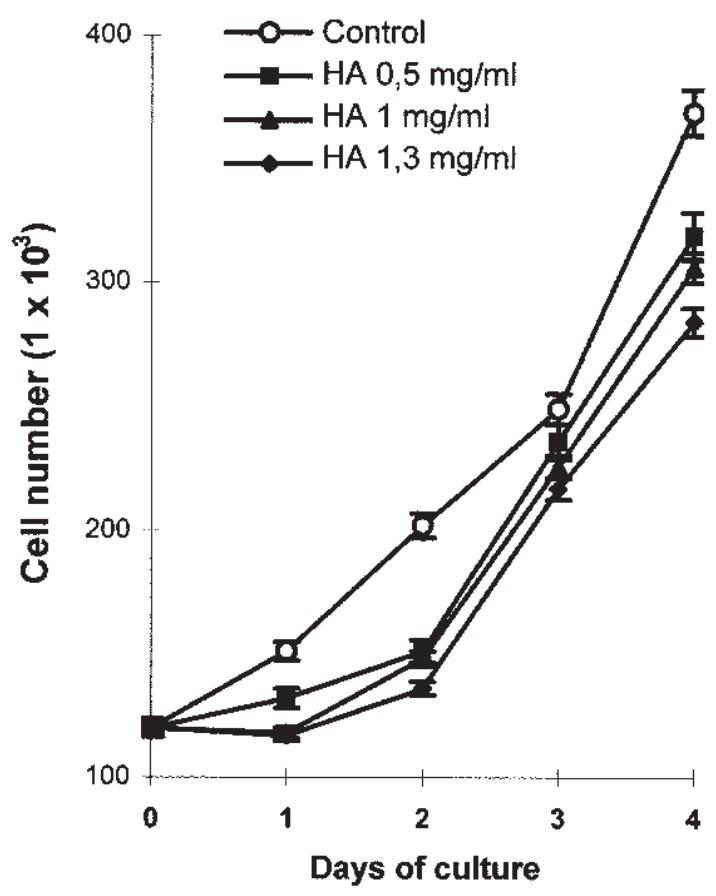

Figure 8. Fibroblast growth was inhibited by HA $\left(7.5 \times 10^{5} \mathrm{Da}\right)$ added to the culture medium. Inhibition was dose dependent and statistically significant at $0.5 \mathrm{mg} / \mathrm{mL}$ HA after 24 and 48 $\mathrm{hr}$, and at 1 and $1.3 \mathrm{mg} / \mathrm{mL} \mathrm{HA}$ at all times considered $(p<0.05)$. Data were the mean of experiments done in triplicate and performed on cell strains obtained from 3 different subjects.

ly expressed on the surface of dermal fibroblasts in vitro, as its expression was not affected by treatment with hyaluronidase nor by the serum concentration. Its expression was higher during the growing phase, and was reduced upon addition of HA and subsequent internalisation of the receptor-ligand complex. Therefore, human dermal fibroblasts express considerable amounts of the HA receptor CD44 on the plasma membrane which seems to be at least partially utilized to internalise and to transport exogenous HA to lysosomes. These data are partially in agreement with those recently reported for bovine chondrocytes, where co-localization of CD44 and HA into cytoplasmic vesicles correlates with HA degradation by acid hydrolases (Aguiar et al, 1999). Moreover, the present data are also partially in agreement with those recently obtained on keratinocytes, where HA did not localize with markers of lysosomes, but was found into endosomal vesicles negative for CD44 (Tammi et al., 2001). The discrepancies among authors could depend on 
the different cell types employed or on the technical difficulty of observing very rapid and complex phenomena. Within 2 minutes at least part of HA was inside the cytoplasm, not in association with CD44; a few minutes later, the great majority of internalised HA co-localised with CD44 into discrete globules; after 20 min incubation, about $60 \%$ of internalised HA was within lysosomes whereas the remaining was into neutral-red-negative vesicles. The effect on cell duplication could be appreciated after a few hours by evaluating the percentage of cells entering the cell cycle. Therefore, binding, internalisation and possible degradation of $\mathrm{HA}$ would seem to precede the effect on cell duplication. The finding that both high and low molecular weight HA induced a similar concentration-dependent inhibition on cell proliferation may suggest that the effect is mediated by HA fragments.

RHAM M ( Receptor for HA Mediated Motility) is another HA receptor claimed to play a fundamental role in HA binding, cell migration and tumor metastasis in human breast cancer (Wang et al. 1998). In our experimental conditions, this receptor was not expressed on the surface of human dermal fibroblasts in normal growing conditions, but was diffusely spread within the cytoplasm. These data are in agreement with the observations by Assmann and coworkers on tumor cells (Assmann et al., 1998), and with recent data on PC12 cells, where RHAMM was shown to be localized to the cytoskeleton, neurites and growth cones (Lynn et al., 2001). For technical difficulty, a clear intracellular co-localization of RHAMM-IHABP and HA could not be obtained, however, within a few minutes upon addition of HA to the culture medium, the distribution of RHAMM-IHABP changed and this $\mathrm{HA}$ receptor appeared concentrated into discrete spots in the peri-nuclear area. Intracellular $\mathrm{HA}$ receptors have been suggested to play a role in cell motility in a particular strain of transformed and normal fibroblasts, where HA was shown to operate only when taken up by cells or microinjected into cells (Collins et al. 1998). The data of the present study would seem to favour this hypothesis, as RHAMM-IHABP receptor was never found on the plasma membrane, but it was found in the cytoplasm. It is worth noting that HA whether present in the extra-cellular space or once internalised did not seem to modify cell-matrix interactions, since cell shape, spreading, as well as vimentin and vinculin organization were not affected by the pres- ence of up to $1 \mathrm{mg} / \mathrm{mL}$ HA (not shown). However, exogenous HA would seem to modify the aggregation properties of actin molecules by inducing the formation of thick cables that could be relevant for cell migration.

It has been recently observed that exogenous HA decreases collagen production by human fibroblasts in vitro (Croce et al., 2001). The present data show that, in the same experimental conditions, HA uptake induces a significant dose-dependent inhibition of cell growth. This may suggest that high fibroblast proliferation would be associated with low concentration of $\mathrm{HA}$ in the extra-cellular space. From data of the literature, the effect of HA on cell growth seems to be greatly dependent on the cell type (Laurent and Fraser 1992). HA has been shown to have an inhibitory effect on the proliferation of CHO cells (Dube et al., 2001), on post-surgical fibroblasts (Klein et al., 1996), on a human malignant mesothelioma cell line exhibiting a fibroblast-like morphology, whereas it had no effect on a similar human malignant mesothelioma cell line exhibiting an epithelial phenotype (Syrokou et al. 1999). Moreover, foetal rabbit fibroblast (Mast et al. 1993) as well as tendon fibroblast proliferation has been shown to be inhibited by exogenous high molecular weight $\mathrm{HA}$ at concentrations similar to those used in the present investigation (Wiig et al. 1996). In the present study, extra-cellular HA would seem to down-regulate the proliferation of adult human skin fibroblasts, by preventing cells from entering the cell cycle rather than influencing the cell cycle as such. The inhibitory effect could be due to the presence of the polysaccharide in the extra-cellular space or the consequence of metabolic events following its internalisation and degradation. The present data seem to support the latter hypothesis, as HA is rapidly internalised and transferred at least partially into lysosomes. Moreover, a masking effect of growth factors by the polysaccharide would seem improbable, as HA has been suggested to favour wound healing by acting as a delivery system for FGF (Radomsky et al. 1998); in addition, apart from heparin, no other proteoglycans nor HA have been shown to interfere with the mitogenic effect of FGF-2 or EGF on neuronal precursors (Caldwell and Svendesen 1998). Interestingly, the most relevant effect of cell duplication was observed during the first two days of culture, then the growth curve runs parallel to the control one. 
Our findings do not agree with the reported data obtained with endothelial cells in vitro, where low and high molecular weight HAs showed a different behaviour, exhibiting respectively an inhibitory or stimulatory effect on cell proliferation (Rahmanian et al. 1997; West and Kumar 1989). In our experimental conditions, both high and low molecular weight HA had similar effects on cell growth, suggesting that $\mathrm{HA}$ as such, or low molecular weight fragments of $H A$, either introduced or derived by intracellular degradation, might be responsible for the observed inhibitory effect on fibroblast proliferation.

In conclusion, extra-cellular $\mathrm{HA}$, when present at relatively high concentrations, has a deep influence on the behaviour of adult human dermal fibroblasts in vitro. It inhibits protein and collagen synthesis by human dermal fibroblasts in vitro (Croce et al., 2001), and the present study shows that soluble HA is rapidly taken up by fibroblasts and exhibits a molecular weight-independent inhibitory effect on cell growth. Moreover, recent data from our laboratory show that, when partially immobilised as it occurs in tissues, HA influences cell-matrix interactions, cell orientation and migration (manuscript submitted). Therefore, HA in normal connective tissues would seem to play pleiotropic roles. It contributes to the three-dimensional organization and to the hydration of the connective tissue extra-cellular matrix thus influencing the physico-chemical properties of the cell environment, and, through cell binding and internalisation, can be a powerful modulator of fibroblast metabolism, migration, orientation and growth.

\section{Acknowledgements}

The financial support by Italian MURST is greatly acknowledged. Authors are grateful to Dr. Nicola Volpi (University of Modena and Reggio Emilia) for having provided $1 \times 10^{4} \mathrm{Da} H \mathrm{~A}$, to Polytech (Trieste) for $1.6 \times 10^{6}$ and $1 \times 10^{3} \mathrm{Da} \mathrm{HA}$ and for fluoresceinated HA, to Fidia Spa (Abano Terme) for $7.5 \times 10^{5} \mathrm{Da}$, and to Dr. Vogel Assmann (London University) for the anti-RHAMM-IHABP antibodies.

\section{References}

Aguiar DJ, Knudson W, Knudson CB. Internalization of hyaluronan receptor CD44 by chondrocytes. Exp Cell Res 1999;252:292-302.

Asplund T, Versnel MA, Laurent TC, Heldin P. Human mesothelioma cells produce factors that stimulate the production of hyaluronan by mesothelial cells and fibroblasts. Cancer Res 1993;53:388-92.

Assmann V, Marshall JF, Fieber C, Hofmann M, Hart IR. The human hyaluronan receptor RHAMM is expressed as an intracellular protein in breast cancer cells. J Cell Sci 1998;111:1685-94.

Boraldi F, Croce AM, Quaglino D, Sammarco R, Carnevali E, Tiozzo R, et al. Cell-matrix interactions of in vitro human skin fibroblasts upon addition of hyaluronan. Tissue Cell 2003; in press.

Caldwell MA, Svendesen CN. Heparin, but not proteoglycans potentiate the mitogenic effects of FGF-2 on mesencephalic precursor cells. Exp Neurol 1998;152:10-6.

Chen J, Grant ME, Schor AM, Schor SL. Differences between adult and foetal fibroblasts in the regulation of hyaluronate synthesis: correlation with migratory activity. J Cell Sci 1989;94:577-84.

Clark RA, Alon R, Springer TA. CD44 and hyaluronan-dependent rolling interactions of lymphocytes on tonsillar stroma. J Cell Biol 1996;134:1075-87.

Collins L, Hall C, Lange L, Ziebell M, Prestwich R, Turley EA. Rapid hyaluronan uptake is associated with enhanced motility: implications for an intracellular mode of action. FEBS Lett 1998;440:444-9.

Croce AM, Dyne K, Boraldi F, Quaglino D Jr, Cetta G, Tiozzo R, et al. Hyaluronan affects protein and collagen synthesis by in vitro human skin fibroblasts. Tissue Cell 2001;33:326-31.

Dube B, Luke HJ, Aumailley M, Prehm P. Hyaluronan reduces migration and proliferation in CHO cells. Biochim Biophys Acta 2001; 1538:283-9.

Ellis IR, Banyard J, Schor SL. Motogenic and biosynthetic response of adult skin fibroblasts to TGF-beta isoforms (-1 -2 and -3) determined by tissue response unit: role of cell density and substratum. Cell Biol Int 23 1999;593-602.

Entwistle J, Hall CL, Turley EA. HA receptors: regulators of signalling to the cytoskeleton. J Cell Biochem 1996;61:569-77.

Evanko SP, Wright TN. Intracellular localization of hyaluronan in proliferating cells. J Histochem Cytochem 1999;47:1331-42.

Fraser JR, Laurent TC, Laurent UB. Hyaluronan: its nature distribution functions and turnover. J Intern Med 1997;242:27-33.

Gressner AM. Proliferation and transformation of cultured liver fatstoring cells (perisinusoidal lipocytes) under conditions of $\beta$-D-xyloside-induced abrogation of proteoglycan synthesis. Exp Mol Pathol 1991;55:143-69.

Heldin P, Asplund T, Ytterberg D, Thelin S, Laurent TC. Characterization of the molecular mechanism involved in the activation of hyaluronan synthetase by platelet-derived growth factor in human mesothelial cells. Biochem J 1992;283:165-70.

Jones NC, Germain A, Riley KE, Bautista C, Taylor W, Wells AF. Borrelia burgdorferi decreases hyaluronan synthesis but increases IL-6 production by fibroblasts. Microb Pathol 1994;16:261-7.

Klein ES, Asculai SS, Ben-Ari GY. Effects of hyaluronic acid on fibroblast behavior in peritoneal injury. J Surg Res 1996;61:473-6.

Knudson CB, Knudson W. Hyaluronan-binding proteins in development tissue homeostasis and disease. FASEB J 1993;7:1233-41.

Knudson W, Biswas C, Li XQ, Nemec RE, Toole BP. The role and regulation of tumor-associated hyaluronan. Ciba Found Symp 1989; 143:150-9.

Kogerman P, Sy MS, Culp LA. Overexpressed human CD44s promotes lung colonization during micrometastasis of murine fibrosarcoma cells: facilitated retention in the lung vasculature. Proc Natl Acad Sci USA 1997;94:13233-8.

Laurent TC, Fraser JR. Hyaluronan. FASEB J 1992;6:2397-404.

Legras S, Levesque JP, Charrad R, Morimoto K, Le-Bousse C, Clay D, et al. CD44-mediated adhesiveness of human hematopoietic progenitors to hyaluronan is modulated by cytokines. Blood 1997;89: 1905-14.

Levesque MC, Haynes BF. Cytokine induction of the ability of human monocyte CD44 to bind hyaluronan is mediated primarily by TNF- $\alpha$ and is inhibited by IL-4 and IL-13. J Immunol 1997;159:6184-94.

Lynn BD, Li X, Cattini PA, Nagy JI. Sequence, protein expression and extracellular-regulated kinase association of the hyaladherin RHAM M (receptor for hyaluronan mediated motility) in PC12 cells. Neurosc Lett 2001;306:49-52.

Mast BA, Diegelmann RF, Krummel TM, Cohen IK. Hyaluronic acid modulates proliferation collagen and protein synthesis of cultured fetal fibroblasts. Matrix 1993;13:441-6.

Mohamadzadeh M, DeGrendele $H$, Arizpe $H$, Estess P, Siegelman M. Proinflammatory stimuli regulate endothelial hyaluronan expression and CD44/HA-dependent primary adhesion. J Clin Invest 1998; 101:97-108 
Ohkawa T, Ueki N, Taguchi T, Shindo Y, Adachi M, Amuro Y, et al. Stimulation of hyaluronan synthesis by tumor necrosis factor- $\alpha$ is mediated by the p50/p65 NF- $\kappa$ B complex in MRC-5 myofibroblasts. Biochim Biophys Acta 1999;1448:416-24.

Quaglino D, Jr, Boraldi F, Barbieri D, Croce A, Tiozzo R, PasqualiRonchetti I. Abnormal phenotype of in vitro dermal fibroblasts from patients with pseudoxanthoma elasticum (PXE). Biochim Biophys Acta 2000;1501:51-62.

Radomsky ML, Thompson AY, Spiro RC, Poser JW. Potential role of Fibroblast Growth Factor in enhancement of fracture healing. Clin Orthop Rel Res 1998;355S:283-93.

Rahmanian M, Pertoft H, Kanda S, Christofferson R, Claesson-Welsh L, Heldin P. Hyaluronan oligosaccharides induce tube formation of a brain endothelial cell line in vitro. Exp Cell Res 1997;237:223-30.

Rockey DC, Chung JJ, McKee CM, Noble PW. Stimulation of inducible nitric oxide synthase in rat liver by hyaluronan fragments. Hepatology 1998;27:86-92.

Rooney P, Kumar S, Ponting J, Wang M. The role of hyaluronan in tumour neovascularization (review). Int J Cancer 1995;6:632-6.

Ropponen K, Tammi M, Parkkinen J, Eskelinen M, Tammi R, Lipponen $\mathrm{P}$, et al. Tumor cell-associated hyaluronan as an unfavorable prognostic factor in colorectal cancer. Cancer Res 1998;58:342-7.

Rudzki Z, Jothy S. CD44 and the adhesion of neoplastic cells. Mol Pathol 1997;50:57-71.

Sattar A, Rooney P, Kumar S, Pye D, West DC, Scott I, et al. Application of angiogenic oligosaccharides of hyaluronan increases blood vessel numbers in rat skin. J Invest Dermatol 1994;103:576-9.

Savani RC, Wang C, Yang B, Zhang S, Kinsella MG, Wight TN, et al. Migration of bovine aortic smooth muscle cells after wounding injury. The role of hyaluronan and RHAMM. J Clin Invest 1995 95:1158-68.

Sugiyama Y, Shimada A, Sayo T, Sakai S, Inoue S. Putative hyaluronan synthase mRNA are expressed in mouse skin and TGF-beta upregulates their expression in cultured human skin cells. J Invest Dermatol 1998;110:116-21.

Suzuki M, Asplund T, Yamashita H, Heldin CH, Heldin P. Stimulation of hyaluronan biosynthesis by platelet-derived growth factor-BB and transforming growth factor- $\beta 1$ involves activation of protein kinase C. Biochem J 1995;307:817-21.

Syrokou A, Tzanakakis G, Tsegenidis T, Hjerpe A, Karamanos NK. Effects of glycosaminoglycans on proliferation of epithelial and fibroblast human malignant mesothelioma cells: a structure-function relationship. Cell Prolif 1999;32:85-99.

Tammi R, Rilla K, Pienimaki JP, MacCallum DK, Hogg M, Luukkonen $M$, et al. Hyaluronan enters keratinocytes by a novel route for catabolism. J Biol Chem 2001;276:35111-22.

Teder P, Nettelbladt 0, Heldin P. Characterization of the mechanism involved in bleomycin-induced increased hyaluronan production in rat lung. Am J Respir Cell Mol Biol 1995;12:181-9.

Toole BP. Hyaluronan in morphogenesis. J Intern Med 1997;242:3540.

Trochon V, Mabilat C, Bertrand P, Legrand Y, Smadja-Joffe F, Soria C, et al. Evidence of involvement of CD44 in endothelial cell proliferation migration and angiogenesis in vitro. Int J Cancer 66 1996;6648.

Tufvesson E, Westergren-Thorsson G. Alteration of proteoglycan synthesis in human lung fibroblasts induced by interleukin-1 $\beta$ and tumor necrosis factor alpha. J Cell Biochem 2000;77:2988-96.

Tuszynski GP, Wang TN, Berger D. Adhesive proteins and the hematogenous spread of cancer. Acta Haematol 1997;97:29-39.

Van de Stolpe A, Van der Saag PT. Intercellular adhesion molecule-1. J Mol Med 1996;74:13-33.

Wang $C$, Thor AD, Moore DH, Zhao $Y$, Kerschmann $R$, Stern $R$ et al. The overexpression of RHAMM a hyaluronan-binding protein that regulates ras signaling correlates with overexpression of mitogenactivated protein kinase and is a significant parameter in breast cancer progression. Clin Cancer Res 1998;4:567-76.

West DC, Kumar S. The effect of hyaluronate and its oligosaccharides on endothelial cell proliferation and monolayer integrity. Exp Cell Res 1989; 183:179-96.

Wheatley SC, Isacke CM, Crossley $\mathrm{PH}$. Restricted expression of the hyaluronan receptor CD44 during postimplantation mouse embryogenesis suggests key roles in tissue formation and patterning. Development 1993;119:295-306.

Wiig M, Abrahamson S0, Lundborg G. Effects of hyaluronan on cell proliferation and collagen synthesis: a study of rabbit tendons in vitro. J Hand Surg 1996;21A:599-604.

Zhang $L$, Underhill CB, Chen L. Hyaluronan on the surface of tumor cells is correlated with metastatic behavior. Cancer Res 1995;55: 428-33. 
M.A. Croce et al. 